\title{
Colder temperature is associated with increased COPD morbidity
}

To the Editor:

Due to global climate change, climatologists anticipate not only a rise in mean yearly ambient temperature, but also an increase in the frequency and intensity of variable weather patterns, including extreme hot and cold weather events $[1,2]$. Overall mortality is higher during winter months $[3,4]$ and half of excessive deaths in the cold season are respiratory in nature [5]. Chronic obstructive pulmonary disease (COPD) is the third leading cause of death worldwide and is linked to high healthcare-associated financial burden $[6$, 7]. Identifying environmental factors that contribute to COPD morbidity is crucial to define adaptive strategies to improve outcomes.

Individuals with COPD face increased mortality, higher rates of hospitalisation and exacerbation, and worse quality of life in cold weather seasons [8-10]. It has been difficult to isolate the specific effect of cold temperature from seasonal effects, and little is known about how fluctuations in cold temperature may impact respiratory health among individuals with COPD. We assessed individuals with COPD during the cold season to determine the effect of daily temperature on disease-specific respiratory health outcomes, including daily symptoms, lung function and rescue inhaler use.

The methods of the COPD and Endotoxin (CODE) study have been described previously [11]. Briefly, participants were former smokers ( $>10$ pack-years, quit $>1$ year), age $\geqslant 40$ years with COPD. Participants provided written informed consent and the Johns Hopkins Institutional Review Board approved the protocol. A total of 84 participants were studied at baseline, 3 and 6 months. At each time interval, participants underwent 1 week of indoor air assessment and completed twice-daily in-home spirometry (PiKo-1, nSpire Health, Inc., Longmont, CO, USA) and diaries assessing activities, symptoms (Breathlessness, Cough, and Sputum Scale (BCSS)) [12] and rescue inhaler use $(0,1,2,3$ or $\geqslant 4$ times daily). Analysis was restricted to data collected during the Baltimore cold weather season (November 1 to March 31) from 2008 to 2011.

Air sampling occurred in the main living area. Indoor temperature and humidity were measured using hourly loggers (HOBO; Onset, Inc., Poccosette, MA, USA). Weekly particulate matter with an aerodynamic diameter $\leqslant 2.5 \mu \mathrm{m}\left(\mathrm{PM}_{2.5}\right)$ and nitrogen dioxide $\left(\mathrm{NO}_{2}\right)$ were measured according to standard methods. Daily outdoor temperature, humidity and pollution $\left(\mathrm{PM}_{2.5}\right.$ and $\left.\mathrm{NO}_{2}\right)$ data were obtained from publicly available datasets $[13,14]$. Daily indoor and outdoor minimum temperature (over a $24 \mathrm{~h}$ period beginning and ending at 08:00 h) were the primary exposure variables in models using generalised estimating equations [15]. Models were adjusted for age, sex, education, visit and percent predicted forced expiratory volume in $1 \mathrm{~s}(\mathrm{FEV} 1)$ measured at enrolment or pack-years of smoking, as appropriate. Additional models included relative humidity, $\mathrm{PM}_{2.5}$ and $\mathrm{NO}_{2}$. Heating source and housing type were added to indoor models. Interaction terms were created between temperature and FEV 1 as well as a dichotomised variable indicating whether participants went outdoors during the $24 \mathrm{~h}$ day. Analyses were performed with Stata/SE statistical software, version12.0 (Stata Corp, College Station, TX, USA).

Of the 84 individuals, 75 had visits during the cold season (41 contributed one and 34 contributed two week-long periods), with 826 total participant days. At baseline, participants had a mean \pm SD age of $69 \pm 8$ years, $56 \%$ were male and $96 \%$ were white. Participants smoked a mean of $54 \pm 27$ pack-years and had a mean FEV1 of $51 \pm 16 \%$ pred. Mean \pm SD BCSS score was $2.7 \pm 2.3$. Mean \pm SD daily morning and evening FEV1 were $1.3 \pm 0.6 \mathrm{~L}$ and $1.2 \pm 0.6 \mathrm{~L}$, respectively. The majority of homes were detached houses $(59 \%)$ or row/terraced homes $(30 \%)$ and used gas $(79 \%)$, oil (16\%) or electric heat pump (12\%) as a heating source.

@ERSpublications

Cold temperatures lead to worse outcomes in those with COPD, even after accounting for other environmental factors http://ow.ly/ltCG30bRWnT

Cite this article as: McCormack MC, Paulin LM, Gummerson CE, et al. Colder temperature is associated with increased COPD morbidity. Eur Respir J 2017; 49: 1601501 [https://doi.org/10.1183/13993003.015012016]. 
Temperatures did not differ by housing type and tended to be cooler in homes using oil heating $\left(67.5^{\circ} \mathrm{F} /\right.$ $\left.19.7^{\circ} \mathrm{C}\right)$ compared to gas $\left(70.3^{\circ} \mathrm{F} / 21.3^{\circ} \mathrm{C}\right)$ or electric heat pump $\left(69.8^{\circ} \mathrm{F}\left(21.0^{\circ} \mathrm{C}\right)\right.$ ). Participants went outdoors on $47 \%$ of days, spending an average $1.6 \pm 1.7 \mathrm{~h}$ outside on these days. The mean $\pm \mathrm{SD}$ minimum daily outdoor temperature was $37.0 \pm 9.6^{\circ} \mathrm{F}\left(2.8 \pm 5.3^{\circ} \mathrm{C}\right)$ and the mean minimum daily indoor temperature was $69.6 \pm 6.4^{\circ} \mathrm{F}\left(20.9 \pm 3.5^{\circ} \mathrm{C}\right.$ ) (figure 1). The minimum daily indoor temperature was not significantly correlated with minimum daily outdoor temperature (Spearman's rho=0.04, $\mathrm{p}=0.25$ ).

In bivariate analysis, decreases in minimum daily outdoor temperature were associated with increases in respiratory symptoms (BCSS), increases in the frequency of rescue inhaler use and decreases in morning and evening lung function (all $\mathrm{p}<0.05$ ). Similar relationships were found after adjustment for confounders. The inclusion of lag terms suggested that decreases in daily minimum outdoor temperature had the greatest effect on the same day for all outcomes and that the effect on symptoms and lung function persisted for up to 3 days post-exposure. Including outdoor relative humidity and pollutants (PM and $\mathrm{NO}_{2}$ ) in the models slightly attenuated the association between outdoor temperature and inhaler use and did not meaningfully alter the associations with symptoms or lung function (table 1). The effect of cold temperature on health outcomes tended to be stronger among individuals who reported going outdoors, although the interaction was not statistically significant ( $p$-interaction $=0.28$ ). Stratified models exploring effect modification by disease severity (FEV $1<50$ or $\geqslant 50 \%$ pred) demonstrated that the effect of outdoor temperature on daily lung function was stronger among those with less severe disease, and the effect on rescue inhaler use was stronger among those with more severe disease. Disease severity did not modify the association between temperature and symptoms.

Daily minimum indoor temperature was not significantly associated with COPD outcomes, except when limiting our results to sampling days when indoor median temperature was below the median temperature of $70^{\circ} \mathrm{F}\left(21^{\circ} \mathrm{C}\right)$, in which case lower indoor minimum temperature was associated with a higher BCSS score. Adjustment for daily indoor relative humidity, heating source, home type and weekly indoor $\mathrm{PM}_{2.5}$ and $\mathrm{NO}_{2}$ concentrations did not impact the results. Accounting for minimum indoor temperature did not meaningfully alter the association between outdoor temperature and respiratory outcomes.

In summary, we found that, during the winter season, colder outdoor temperatures were associated with increased respiratory symptoms, increased rescue inhaler use and decreased lung function in former smokers with COPD. For example, a $10^{\circ} \mathrm{F}\left(5.5^{\circ} \mathrm{C}\right)$ decrease in the daily minimum outdoor temperature was associated with an increase in inhaler use, a 0.17 point increase in BCSS score and a mean decrease of $38 \mathrm{~mL}$ and $26 \mathrm{~mL}$ in morning and evening FEV1, respectively. Individuals in our study were susceptible to the effects of cold outdoor temperature exposure, despite limited time spent outdoors, suggesting that the adverse effects may be a result of brief excursions in cold outdoor environments.

Our study supports the findings of larger epidemiological studies that demonstrate a higher rate of COPD exacerbations in winter months, suggesting that exacerbations may be triggered by cold temperatures [ 10 , 16]. However, few studies have looked at the individual-level morbidity indictors, including rescue medication use, symptoms and daily lung function, that may precede healthcare utilisation following cold temperature exposure. Among 76 individuals with COPD, DonALDSOn et al. [17] found FEV1 to be $45 \mathrm{~mL}$ lower during the coldest winter week as compared to the warmest summer week of monitoring. Although previous studies have included FEV1 as a covariate in multivariate models, we are unaware of studies that report whether the effect of cold temperature differs by lung function. While there was evidence of effect

FIGURE 1 Distributions of daily indoor and outdoor minimum temperature in the cold season.

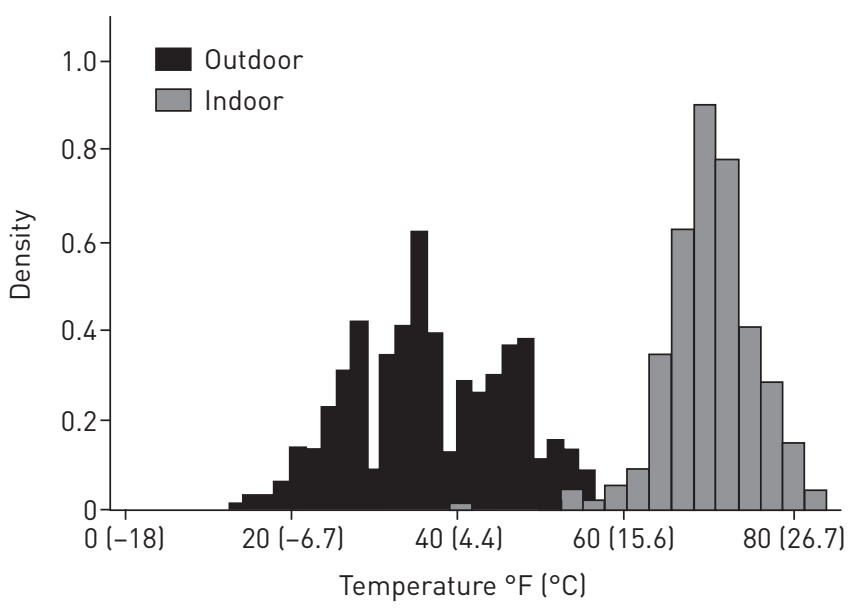




\begin{tabular}{|c|c|c|c|}
\hline & Coefficient ${ }^{\Uparrow}$ & $95 \% \mathrm{Cl}$ & p-value \\
\hline \multicolumn{4}{|l|}{ Breathlessness, cough and sputum scale } \\
\hline Daily temperature (limited model ${ }^{\#}$ ) & 0.17 & $0.04,0.29$ & 0.01 \\
\hline Daily temperature (with relative humidity, $\mathrm{NO}_{2}, \mathrm{PM}_{2.5}$ ) & 0.18 & $0.04,0.32$ & 0.01 \\
\hline Lag 1 & 0.13 & $0.03,0.23$ & 0.01 \\
\hline Lag 2 & 0.11 & $0.02,0.20$ & 0.02 \\
\hline Lag 3 & 0.10 & $0.01,0.18$ & 0.03 \\
\hline \multicolumn{4}{|l|}{ Rescue inhaler use } \\
\hline Daily temperature (limited model ${ }^{\#}$ ) & 0.09 & $0.02,0.16$ & 0.01 \\
\hline Daily temperature (with humidity, $\mathrm{NO}_{2}, \mathrm{PM}_{2.5}$ ) & 0.07 & $-0.001,0.15$ & 0.05 \\
\hline Lag 1 & 0.04 & $-0.02,0.10$ & 0.17 \\
\hline Lag 2 & 0.02 & $-0.03,0.07$ & 0.49 \\
\hline Lag 3 & 0.02 & $-0.03,0.07$ & 0.39 \\
\hline \multicolumn{4}{|l|}{ Lung function (morning FEV 1 ) L } \\
\hline Daily temperature (limited model ${ }^{\#}$ ) & -0.038 & $-0.060,-0.015$ & 0.001 \\
\hline Daily temperature (with humidity, $\mathrm{NO}_{2}, \mathrm{PM}_{2.5}$ ) & -0.052 & $-0.077,-0.027$ & $<0.001$ \\
\hline Lag 1 & -0.039 & $-0.061,-0.017$ & $<0.001$ \\
\hline Lag 2 & -0.025 & $-0.043,-0.007$ & 0.007 \\
\hline Lag 3 & -0.016 & $-0.033,0.001$ & 0.07 \\
\hline \multicolumn{4}{|l|}{ Lung function (evening FEV 1 ) L } \\
\hline Daily temperature (limited model ${ }^{\#}$ ) & -0.026 & $-0.050,-0.003$ & 0.03 \\
\hline Daily temperature (with humidity, $\mathrm{NO}_{2}, \mathrm{PM}_{2.5}$ ) & -0.038 & $-0.063,-0.012$ & 0.004 \\
\hline Lag 1 & -0.017 & $-0.036,0.002$ & 0.09 \\
\hline Lag 2 & -0.016 & $-0.034,0.001$ & 0.07 \\
\hline Lag 3 & -0.010 & $-0.026,0.007$ & 0.26 \\
\hline
\end{tabular}

FEV1: forced expiratory volume in $1 \mathrm{~s}$; $\mathrm{PM}_{2.5}$ : particulate matter less than $2.5 \mu \mathrm{m}$ in aerodynamic diameter; $\mathrm{NO}_{2}$ : nitrogen dioxide. ${ }^{\#}$ : models include visit, age, sex, education, baseline FEV1 (pack-years was used instead of baseline $\mathrm{FEV} 1$ in lung function models); ${ }^{\text {n: }}$ : changes are expressed per $10^{\circ} \mathrm{F}\left(5.5^{\circ} \mathrm{C}\right)$ decrease in outdoor temperature. Relationships that were statistically significant $(p<0.05)$ are indicated in bold.

modification by disease severity in our analysis, the interpretation of these results is not clear. In earlier studies that compared outcomes across seasons, it has been difficult to tease out the effects of temperature changes from other seasonal differences. Our study expands current knowledge by limiting analysis to the cold season, therefore minimising confounding by other seasonal factors.

There are several notable limitations of this study. Our sample size is relatively small and each participant contributed 7-16 days of repeated measures. Although we found that the association between outdoor temperature and symptoms and lung function persisted for 2-3 days, limited power may restrict the ability to fully explore lagged effects. The study population was drawn from the Baltimore area, which may limit generalisability to other geographic areas, and participants who agreed to be part of this study may differ from those who did not. We do not have demographic information on those who declined to participate. Participant adherence to long-acting COPD medications was not assessed. Participants who were acutely ill were not scheduled for home visits, making it unlikely that respiratory infection was a confounder of the relationship between temperature and respiratory outcomes, but we were unable to confirm this as microbiological data were not collected.

Although we did not find an association between indoor cold temperature and COPD outcomes across the entire sample, homes were relatively warm and may not represent conditions in households where heating resources are scarce. However, when limiting analysis to sampling days below the median temperature, we found an adverse effect of indoor temperature on respiratory symptoms. Prior research has suggested that there may exist a threshold below which colder temperatures adversely impact respiratory health $[10,18]$ and several studies have identified $18{ }^{\circ} \mathrm{C}\left(64^{\circ} \mathrm{F}\right)$ as a potential threshold of indoor temperature below which adverse health effects may occur $[19,20]$. Similarly, in a 1 week study of 148 participants with COPD living in the UK, fewer days with $9 \mathrm{~h}$ of warmth at $21^{\circ} \mathrm{C}\left(70^{\circ} \mathrm{F}\right)$ in the living room was associated with worse quality of life as measured by the St George's Respiratory Questionnaire [21]. Our study was not designed to identify potential temperature thresholds, but findings among the cooler half of the indoor temperature days are generally consistent with prior studies. Further investigation is needed to confirm 
hazardous ranges of temperature extremes and to incorporate findings into public health advisories that address the use of personal protective barriers and public infrastructure improvements $[5,22]$. It has been suggested that cold temperature exposure may result in several unique airway responses, including rhinorrhoea and congestion, airway epithelial damage leading to changes in airway structure and function, and both direct and reflex bronchoconstriction of the lower airways secondary to cooling of the facial skin and upper airways $[23,24]$, but a better understanding of the mechanism by which cold temperature induces COPD morbidity is warranted. This study highlights the current impact of cold-related morbidity in individuals with COPD and the potential for even greater morbidity given the projected increase in extreme cold weather events. Identifying strategies to minimise such cold temperature exposure may be a means of improving outcomes in the vulnerable COPD population.

Meredith C. McCormack ${ }^{1,3}$, Laura M. Paulin ${ }^{1,3}$, Christine E. Gummerson ${ }^{1}$, Roger D. Peng ${ }^{2}$, Gregory B. Diette ${ }^{1}$ and Nadia N. Hansel ${ }^{1}$

${ }^{1}$ Johns Hopkins University School of Medicine, Pulmonary and Critical Care Medicine, Baltimore, MD, USA. ${ }^{2}$ Johns Hopkins Bloomberg School of Public Health, Dept of Biostatistics, Baltimore, MD, USA. ${ }^{3}$ Co-first authors.

Correspondence: Meredith C. McCormack, Pulmonary and Critical Care Medicine, Johns Hopkins University, 1830 East Monument Street, 5th Floor, Baltimore, MD 21205, USA. E-mail: mmccor16@jhmi.edu

Received: May 062016 | Accepted after revision: March 252017

Support statement: The authors are supported by the following grants: NIEHS grants F32ES022115, K23ES025781, K24ES021098, P01ES018176, P50ES015903, R01ES022607, R01ES023500, R21ES015781, R21ES024021 and R21ES025840, NIMHD grant P50MD010431 and EPA grant RD83451001. Funding information for this article has been deposited with the Crossref Funder Registry.

Conflict of interest: Disclosures can be found alongside this article at erj.ersjournals.com

\section{References}

1 Stocker T, Qin D, Plattner G, et al. Climate Change 2013: The Physical Science Basis. Contribution of Working Group I to the Fifth Assessment Report of the Intergovernmental Panel on Climate Change. Cambridge, Cambridge University Press, 2013.

2 Crimmins A, Balbus J, Gamble J, et al. The Impacts of Climate Change on Human Health in the United States: A Scientific Assessment. Washington, DC, Global Change Research Program, 2016.

3 Carson C, Hajat S, Armstrong B, et al. Declining vulnerability to temperature-related mortality in London over the 20th century. Am J Epidemiol 2006; 164: 77-84.

4 Wilkinson P, Pattenden S, Armstrong B, et al. Vulnerability to winter mortality in elderly people in Britain: population based study. BMJ 2004; 329: 647 .

5 The Eurowinter Group. Cold exposure and winter mortality from ischaemic heart disease, cerebrovascular disease, respiratory disease, and all causes in warm and cold regions of Europe. Lancet 1997; 349: 1341-1346.

6 Loddenkemper R. European Lung White Book. The First Comprehensive Survey on Respiratory Health in Europe. Sheffield, European Respiratory Society, 2003.

7 Guarascio AJ, Ray SM, Finch CK, et al. The clinical and economic burden of chronic obstructive pulmonary disease in the USA. Clinicoecon Outcomes Res 2013; 5: 235-245.

8 Donaldson GC, Goldring JJ, Wedzicha JA. Influence of season on exacerbation characteristics in patients with COPD. Chest 2012; 141: 94-100.

9 Viggers H, Howden-Chapman P, Ingham T, et al. Warm homes for older people: aims and methods of a randomised community-based trial for people with COPD. BMC Public Health 2013; 13: 176.

10 Jenkins CR, Celli B, Anderson JA, et al. Seasonality and determinants of moderate and severe COPD exacerbations in the TORCH study. Eur Respir J 2012; 39: 38-45.

11 Hansel NN, McCormack MC, Belli A, et al. In-home air pollution is linked to respiratory morbidity in former smokers with COPD. Am J Respir Crit Care 2013; 187: 1085-1090.

12 Leidy NK, Rennard SI, Schmier J, et al. The Breathlessness, Cough, and Sputum Scale: the development of empirically based guidelines for interpretation. Chest 2003; 124: 2182-2191.

13 National Oceanic and Atmospheric Administration. National Centers for Environmental Information. 2016. Available from: https://www.ncdc.noaa.gov/cdo-web/datatools/findstation Date last accessed: January 18, 2016.

14 US Environmental Protection Agency Air Quality System Database. 2015. www3.epa.gov/ttn/airs/airsaqs.

15 Diggle PJ, Heagerty PJ, Liang K-Y, et al. Analysis of Longitudinal Data. 2nd Edn. Oxford, Oxford University Press, 2002.

16 Tseng CM, Chen YT, Ou SM, et al. The effect of cold temperature on increased exacerbation of chronic obstructive pulmonary disease: a nationwide study. PLOS ONE 2013; 8: e57066.

17 Donaldson GC, Seemungal T, Jeffries DJ, et al. Effect of temperature on lung function and symptoms in chronic obstructive pulmonary disease. Eur Respir J 1999; 13: 844-849.

18 Keatinge WR, Donaldson GC. Mortality related to cold and air pollution in London after allowance for effects of associated weather patterns. Environ Res 2001; 86: 209-216.

19 Jevons R, Carmichael C, Crossley A, et al. Minimum indoor temperature threshold recommendations for English homes in winter - a systematic review. Public Health 2016; 136: 4-12.

20 World Health Organization. Housing, Energy and Thermal Comfort: A Review of 10 Countries Within the WHO European Region. Geneva, WHO, 2007.

21 Osman LM, Ayres JG, Garden C, et al. Home warmth and health status of COPD patients. Eur J Public Health 2008; 18: 399-405. 
22 Conlon KC, Rajkovich NB, White-Newsome JL, et al. Preventing cold-related morbidity and mortality in a changing climate. Maturitas 2011; 69: 197-202.

23 Koskela HO, Koskela AK, Tukiaineu HO. Bronchoconstriction due to cold weather in COPD. The roles of direct airway effects and cutaneous reflex mechanisms. Chest 1996; 110: 632-636.

24 Koskela HO. Cold air-provoked respiratory symptoms: the mechanisms and management. Int J Circumpolar Health 2007; 66: 91-100. 